\title{
The Disease Ecology, Epidemiology, Clinical Manifestations, and Management of Trichinellosis Linked to Consumption of Wild Animal Meat
}

\author{
James H. Diaz, MD, MPH\&TM, DrPH, FACOEM, FASTMH ${ }^{1}$; Rebecca J. Warren, BS ${ }^{1}$; Marissa J. Oster, BS ${ }^{1,2}$ \\ ${ }^{1}$ Program in Environmental and Occupational Health Sciences, School of Public Health, Louisiana State University Health Sciences Center (LSUHSC), \\ New Orleans, LA; ${ }^{2}$ Louisiana State University School of Veterinary Medicine, Baton Rouge, LA
}

\begin{abstract}
Historically, human trichinellosis was caused by Trichinella spiralis and transmitted to humans by consumption of undercooked domestic pork. Today, most cases of trichinellosis are caused by other Trichinella species and transmitted by consumption of raw or undercooked wild game meats. Given the increasing global prevalence of wild animal meat-linked trichinellosis, the objectives of this review are: 1) to describe the life cycle and global distribution of Trichinella worms; 2) to describe the changing epidemiology of trichinellosis; 3) to describe the clinical phases of trichinellosis; 4) to recommend the latest diagnostic tests; and 5) to recommend treatment and prevention strategies. Internet search engines were queried with keywords as subject headings to meet the objectives of this review. Although trichinellosis surveillance systems and laws regulating commercial pork production have limited $T$ spiralis-caused trichinellosis in Europe and the United States, trichinellosis due to consumption of raw and undercooked wild boar and feral hog meat continues to occur throughout Southeast Asia. Trichinellosis due to consumption of raw or undercooked meats of other infected game, such as bear, deer, moose, and walrus, continues to occur worldwide. Only adherence to hygienic practices when preparing wild game meats and cooking wild game meats to recommended internal temperatures can prevent transmission of trichinellosis to humans. Wilderness medicine clinicians should be prepared to advise hunters and the public on the risks of game meat-linked trichinellosis and on how to diagnose and treat trichinellosis to prevent fatal complications.
\end{abstract}

Keywords: helminthiasis, foodborne, trichinosis

\section{Introduction}

Trichinellosis (formerly trichinosis) is a parasitic infection caused by migrating larvae of Trichinella nematodes. ${ }^{1}$ Trichinella worms are among the world's most widely distributed zoonotic parasites, with a large animal reservoir in amphibians, reptiles, rodents, birds, and mammals. ${ }^{1}$ Historically, human trichinellosis was caused by Trichinella spiralis, the pork worm, and transmitted to humans by consumption of undercooked domestic pork and pork-

Corresponding author: James H. Diaz, MD, Dr.PH, Environmental and Occupational Health Sciences, School of Public Health, Louisiana State University Health Sciences Center in New Orleans, Louisiana, 2020 Gravier Street, Third Floor, New Orleans, Louisiana 70112; e-mail: jdiaz@1suhsc.edu.

Submitted for publication July 2019.

Accepted for publication December 2019. containing products, especially sausage. ${ }^{2,3}$ Today, trichinellosis is less often associated with consumption of $T$ spiralis-infected commercial pork products in the United States, Europe, and Asia due to hygienic advances in the domestic pork industry. ${ }^{2,3}$ Trichinellosis is now transmitted more often by the consumption of raw or undercooked wild and home-raised game meats, such as wild boar, bear, deer, moose, and walrus. ${ }^{2-5}$

Given the increasing global prevalence of trichinellosis, the objectives of this review are: 1) to describe the parasitology, life cycle, geographic distribution, and zoonotic reservoirs of Trichinella species nematodes; 2) to describe the changing disease ecology and epidemiology of trichinellosis and its wilderness-related risk factors; 3 ) to describe the parenteral, enteral, and muscular encysting phases of trichinellosis and their clinical manifestations; 4) to recommend the latest diagnostic laboratory tests for 
Table 1. Scientific articles reviewed, referenced, and stratified by types

\begin{tabular}{|c|c|c|c|c|c|c|}
\hline & $\begin{array}{l}\text { Review } \\
\text { articles }\end{array}$ & $\begin{array}{l}\text { Descriptive } \\
\text { epidemiological } \\
\text { (surveillance) } \\
\text { investigations }\end{array}$ & $\begin{array}{l}\text { Serological } \\
\text { or molecular } \\
\text { investigations }\end{array}$ & $\begin{array}{l}\text { Outbreak } \\
\text { investigations }\end{array}$ & $\begin{array}{l}\text { Parasitology } \\
\text { reports }\end{array}$ & $\begin{array}{l}\text { Case reports } \\
\text { and case } \\
\text { series }\end{array}$ \\
\hline $\begin{array}{l}\text { Articles reviewed }^{a} \\
\quad(\mathrm{n}=60)\end{array}$ & 12 & 10 & 12 & 8 & 12 & 6 \\
\hline $\begin{array}{l}\text { Articles referenced } \\
\qquad(\mathrm{n}=45)\end{array}$ & 8 & 7 & 9 & 8 & 9 & 4 \\
\hline
\end{tabular}

${ }^{a}$ Articles not reviewed: parasitic nematode reviews, clinical-pathological case conference reports, and opinion-editorial articles.

trichinellosis; and 5) to recommend management and prevention strategies for trichinellosis to wilderness medicine clinicians.

\section{Methods}

Internet search engines including PubMed, Medline, Ovid, Google, Google Scholar, and Cochrane were queried with the keywords as subject headings to meet the objectives of this narrative review. In addition to the title words, keywords included helminthiasis (foodborne) and trichinosis. The study period was defined as 1970 to 2018 . The articles selected to meet these objectives included review articles; case reports and series; outbreak investigations; observational, longitudinal, and surveillance studies; and parasitological reports (Table 1). Articles excluded from review included parasitic nematode reviews, clinical-pathological conference reports, and opinion-editorial articles. These selected methodologies met all recommended criteria for narrative reviews, including several keywords, use of 2 or more Internet search engines, defined study period, and article inclusion and exclusion criteria. ${ }^{6}$ Institutional review board approval was not required for this investigation, which was an analysis of prior peer-reviewed, published scientific articles.

\section{Results}

\section{THE PARASITOLOGY AND LIFE CYCLE OF TRICHINELLA SPECIES}

There are 10 currently known species of Trichinella ( 8 genotyped and 2 not genotyped) with a worldwide geographic distribution and a wide range of asymptomatically infected reservoir host animals (Table 2). ${ }^{7}$ Although Trichinella spiralis remains a common cause of human infection in the United States and Europe due to its ability to parasitize rodents and feral swine, other Trichinella species are causing more frequent infections elsewhere and have more restricted animal reservoirs and ranges, such as Trichinella patagoniensis, recently discovered in cougars in Argentina. $^{7,8}$

Trichinella worms are among the smallest species of nematodes, with adult males averaging $1.2 \mathrm{~mm}$ in length and larger females averaging $2.2 \mathrm{~mm}$ in length. ${ }^{9}$ Adult worms mate in the small intestinal mucosa when mature and have an average life span of 4 to 6 wk during the initial enteral phase of infection. ${ }^{9}$ Female worms can produce up to 1500 larvae before their death and fecal elimination. ${ }^{9}$

The life cycle of Trichinella in man and host animals has 3 sequential phases: the enteral phase, parenteral phase, and encysting phase (Figure 1). The life cycle of all species begins during the enteral phase in the stomach and small intestines, when gastric acid and pepsin chemically dissolve and release larvae encysted in striated animal muscle that is consumed raw or undercooked. ${ }^{9}$ Freed larvae invade the small intestinal mucosa, mature, and mate within $1 \mathrm{wk}$. Gravid females release larvae that enter lymphatic channels for circulation to striated muscles to encyst within another week, with or without a surrounding capsule. ${ }^{9}$ Of the 10 species of Trichinella worms, 5 form encapsulated cysts in striated muscle, and 5 do not (Table 2). ${ }^{7}$

Circulating larvae can encyst anywhere in the body, including the myocardium and extraocular muscles, but they prefer to encyst in large, highly vascularized striated muscles, such as the tongue, diaphragm, psoas, pectoralis major, and gluteus maximus. ${ }^{5}$ After entering striated muscle fibers through capillaries, a cytokine-stimulated release of vascular endothelial growth factor enables encapsulated cysts to form nurse-cell complexes. ${ }^{10}$ The nurse-cell complexes contain collagen-like substances that further surround the cyst, protect it from immune attack and subfreezing temperatures, and permit it to remain sequestered in striated muscle for years. ${ }^{10}$ The parasite's life cycle is usually completed within $2 \mathrm{wk}^{9}$ 
Table 2. Trichinella species, encysted muscle forms, geographic distributions, and animal reservoirs

\begin{tabular}{|c|c|c|c|}
\hline Species & $\begin{array}{l}\text { Encysted muscle } \\
\text { forms }\end{array}$ & $\begin{array}{l}\text { Geographic } \\
\text { distributions }\end{array}$ & Host animal reservoirs \\
\hline Trichinella britovi & Encapsulated & $\begin{array}{l}\text { Europe, Asia, } \\
\text { Africa }\end{array}$ & $\begin{array}{l}\text { Wild and domestic swine, wild carnivores (bears, foxes, hyenas, } \\
\text { lynxes, wolves) }\end{array}$ \\
\hline T murrelli & Encapsulated & North America & $\begin{array}{l}\text { Black bears, grizzly bears, raccoons, red foxes, bobcats, coyotes, } \\
\text { cougars, moose, wild boar }\end{array}$ \\
\hline T nativa & Encapsulated & $\begin{array}{l}\text { Arctic and subarctic } \\
\text { regions worldwide }\end{array}$ & $\begin{array}{l}\text { Arctic foxes, polar bears, black bears, brown bears, grizzly bears, } \\
\text { walruses, sea ice-associated seals, wolves, other wild carnivores }\end{array}$ \\
\hline Tnelsoni & Encapsulated & Africa & Wild carnivores (wild dogs, hyenas, lions, tigers) \\
\hline T papuae & Nonencapsulated & $\begin{array}{l}\text { Papua New Guinea, } \\
\text { Taiwan, Thailand }\end{array}$ & Wild and domestic swine, saltwater crocodiles, soft-shelled turtles \\
\hline$T$ patagoniensis & Encapsulated & Argentina & Cougars \\
\hline Tpseudospiralis & Nonencapsulated & Worldwide & Birds, mammals, reptiles \\
\hline T spiralis & Encapsulated & Worldwide & Wild and domestic swine, horses \\
\hline$T$ zimbabwensis & Nonencapsulated & Africa & Nile crocodiles, monitor lizards \\
\hline $\begin{array}{l}\text { Trichinella } \mathrm{T} 8 \\
\text { (unnamed } \\
\text { genotype) }\end{array}$ & Nonencapsulated & $\begin{array}{l}\text { Africa, South } \\
\text { Africa, Namibia }\end{array}$ & Lions, spotted hyenas (not detected in humans at present) \\
\hline $\begin{array}{l}\text { Trichinella T9 } \\
\text { (unnamed } \\
\text { genotype) }\end{array}$ & Nonencapsulated & Japan & Bears, wild carnivores \\
\hline
\end{tabular}

\section{THE DISEASE ECOLOGY AND WILDERNESS-RELATED RISK FACTORS FOR TRICHINELLOSIS}

Rodents are primarily responsible for maintaining the epizoonosis of trichinellosis in nature. ${ }^{9}$ Larger predators feed on infected rodents or carrion from other infected animals and continue to maintain the epizoonotic cycle of trichinellosis. Longer-lived predatory animals in the wild are more likely to become infected with Trichinella species over time.

Physiological adaptations of muscle-stage larvae allow Trichinella species, especially those in the encapsulated clade, to remain viable in decaying meat, frozen meat, and infected animal carcasses for months to years. Thus, a single animal carcass harboring Trichinella larvae can infect hundreds of other carrion-feeding animals. Climatic factors can also affect the persistence of larvae. In encapsulated species that are adapted to subfreezing temperatures, such as $T$ britovi in infected black and grizzly bears and $T$ nativa in infected polar bears and walruses, the cysts can survive in frozen game meat for many years. ${ }^{11-13}$ The exact length of time that encapsulated cysts can remain viable in frozen animal muscle is unknown, but it may be influenced by parasite burden and preferred encysting-site muscles, such as the tongue and diaphragm. ${ }^{13,14}$

Human behavior also has a large impact on the sylvatic cycle of trichinellosis. Hunting practices of abandoning animal carcasses, improperly discarding unwanted muscle such as the tongue and diaphragm after field dressing of game, and feeding animal waste to hunting dogs all promote subsequent transmission of trichinellosis to scavenging wild animals and to domestic animals, especially dogs. ${ }^{14-18}$ Manmade environmental changes, such as farmland-to-forest projects in Eastern Europe over the past century, have caused a surge in wild boar populations, promoted the return and popularity of wild boar hunting, and resulted in an increasing prevalence of human trichinellosis in these regions. ${ }^{19-22}$

In addition to feral swine and wild boar, many other feral and wild carnivores can host Trichinella species and transmit trichinellosis to humans when their infected meat is consumed undercooked or raw. ${ }^{17,23}$ In 2008, investigators collected 59 raccoons and 42 coyotes in Wisconsin, performed cyst digestion studies on the animal tongues, and detected Trichinella murrelli cysts in $19 \%$ of the raccoons and $26 \%$ of the coyotes. ${ }^{17}$

Even some herbivores, such as horses, can harbor Trichinella cysts. In 1985, a major outbreak of horsemeatassociated trichinellosis was reported from Paris. ${ }^{24}$ Three hundred twenty-five individuals met the case definition of infection as confirmed by muscle biopsy, serology, or clinical presentation. Two elderly patients died, and 1 pregnant patient miscarried during the first trimester. All 325 patients reported consuming horsemeat, with $99 \%$ consuming horsemeat raw or rare. All patients purchased horsemeat from 2 butcher shops, with each shop having received half of a single horse carcass from a slaughterhouse in Connecticut. The butchers from the 2 implicated shops and their 


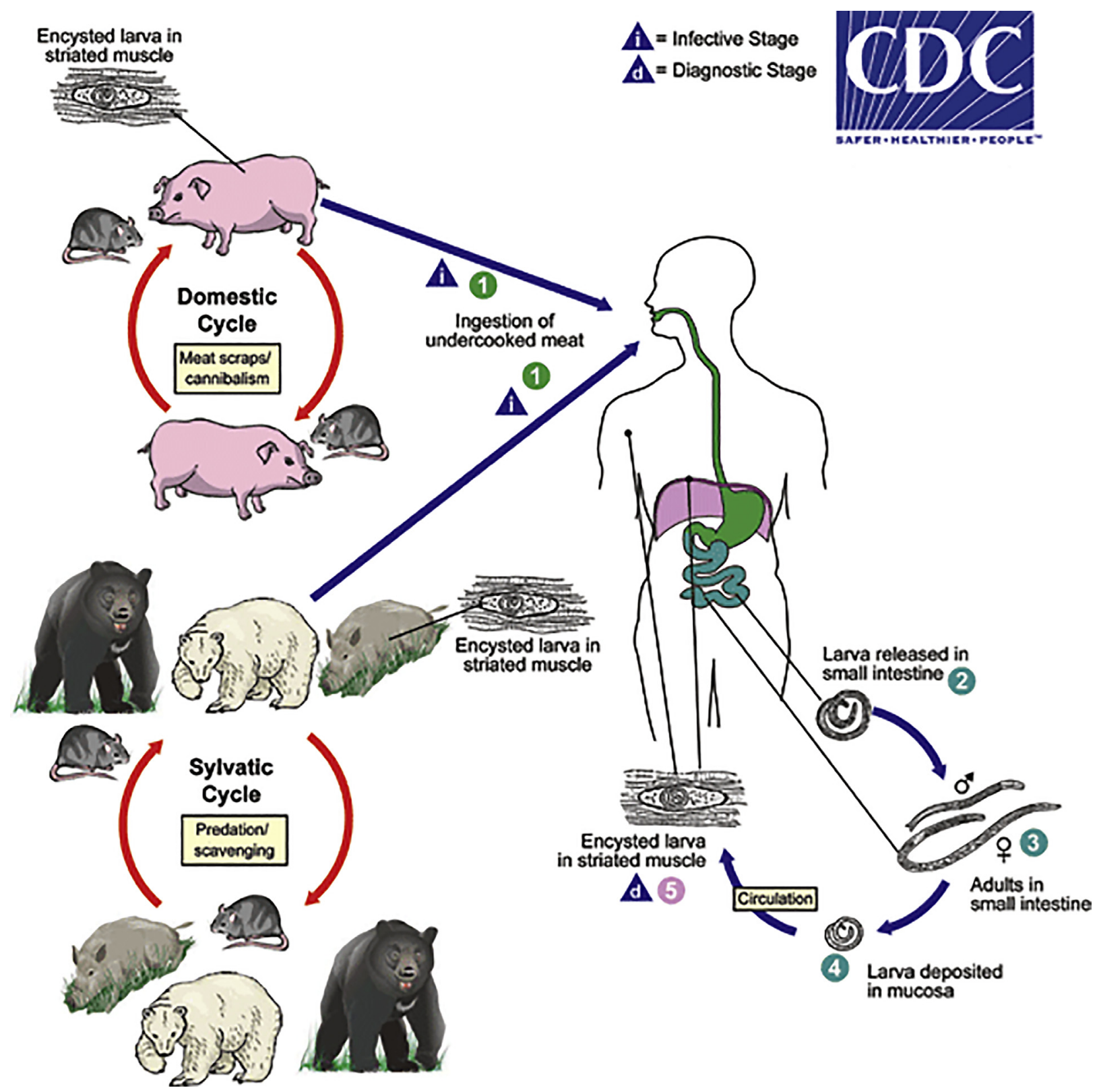

Figure 1. The domestic and sylvatic live cycles of Trichinella species. United States Centers for Disease Control and Prevention (CDC). Available at: https://www.cdc.gov/dpdx/trichinellosis/. Public domain.

families also had trichinellosis. Unfortunately, no meat from the implicated horse was available for inspection.

Because of the increasing number of outbreaks of horsemeat-associated trichinellosis in France, Italy, and Eastern Europe, Danish investigators conducted 3 nested studies to determine how horses, long considered herbivores, acquired a meat-borne parasite. ${ }^{25}$ First, a descriptive epidemiological study revealed that feeding animal products to horses was common practice among horse owners. Second, a series of prospective trials involving experimental feeding of meat products to 219 horses demonstrated that $32 \%$ would consume meat patties. Third, to confirm that horses would eat infected meat under normal farm conditions, investigators fed 3 horses infected ground pork balls containing 1100 Trichinella larvae. All 3 animals developed trichinellosis, as confirmed serologically and at necropsy. The investigators concluded that horses are more willing to consume meat than formerly realized, that the intentional feeding of animal products and kitchen waste was common practices among horse owners, and that horses contracted 
trichinellosis from consumption of infected meat. The investigators recommended that the same Trichinella-free assurances applied by regulations to domestic pork be applied to horsemeat destined for human consumption. Although horsemeat consumption is uncommon in the United States, horsemeat is frequently consumed in Europe and often prepared raw or lightly cooked as steaks, soups, and ground meatballs or patties. ${ }^{24,25}$

\section{THE EPIDEMIOLOGY OF TRICHINELLOSIS}

The principle transmission mechanism of Trichinella to humans is through the consumption of raw or undercooked meat from a broad range of infected animals. There is no evidence to support human-to-human transmission of trichinellosis. However, cases have been reported following the transmission of encysted larvae through fomites, such as carving tables, cutting boards, knives, and other utensils used to prepare contaminated raw meat and subsequently used to prepare raw food dishes such as salads. ${ }^{2,3}$

Cases of trichinellosis have declined significantly in many countries, including the United States, because of rigid sanitary regulations imposed on commercial swine feeding lots, especially a ban on feeding animal waste and uncooked garbage to pigs. $^{2,3}$ In 2011, investigators reported a total of 65,818 cases of trichinellosis and 42 deaths in 41 countries over the period of 1986 to 2009. ${ }^{23}$ Today most outbreaks of trichinellosis in Asia, Europe, and the United States are associated with the consumption of raw or undercooked meats from wild amphibians, birds, reptiles, and game animals such as bear, wild boar, deer, and walrus. ${ }^{19-23}$

In a 2015 review of 90 trichinellosis cases from 24 states and the District of Columbia reported to the US Centers for Disease Control and Prevention over the period of 2008 to 2012, investigators confirmed 84 cases, about half of which $(\mathrm{n}=40)$ occurred in 5 outbreaks. ${ }^{2}$ The mean annual incidence rate of trichinellosis in the United States was 0.1 case per 1 million persons, with a median number of 15 cases per year. ${ }^{2}$ Domestic, home-raised, and feral swine products were associated with $26 \%$ of cases $(n=22)$, with $45 \%(\mathrm{n}=10)$ traced to commercial pork products, $27 \%$ $(\mathrm{n}=6)$ traced to wild boar, $5 \%(\mathrm{n}=1)$ traced to home-raised swine, and 23\% $(\mathrm{n}=5)$ unspecified. $^{2}$ More cases $(54 \%$, $\mathrm{n}=45$ ) were linked to meats other than pork, with $91 \%$ $(n=41)$ linked to bear meat, $4 \%(n=2)$ linked to deer meat, and $4 \%(n=2)$ linked to ground wild animal meat. ${ }^{2}$ The authors concluded that: 1) the consumption of wild game meats was the most important source of infection in the United States, exceeding pork-linked cases, and 2) hunters and consumers of wild game meats should be better educated about the risks associated with eating raw and undercooked animal meat. ${ }^{2}$
Mirroring the US experience, commercial pork productlinked cases of trichinellosis declined and game meat-linked cases increased in Europe and Asia during the reporting period of 2012 to 2016. In a follow-up investigation of a 2012 outbreak of trichinellosis in a region of central Italy (Lucca Province, Tuscany) that had not reported a case of trichinellosis in $20 \mathrm{y}, 38$ persons reported eating uncooked homemade sausages from a locally hunted and butchered wild boar. ${ }^{20}$ Among the 38, 34 patients were serologically positive for Trichinella britovi infection, and 32 developed clinical manifestations of trichinellosis (Table 2). ${ }^{20}$

Between 1975 and 2016, there were no reported outbreaks of trichinellosis linked to domestic pork consumption in Japan. ${ }^{26}$ However, there were 4 outbreaks of trichinellosis linked to consumption of raw or undercooked bear meat during that period. ${ }^{26}$ In a 2018 follow-up investigation of the last outbreak of locally hunted bear meatlinked trichinellosis in Japan, 28 patients reported eating undercooked bear meat in salads. ${ }^{26}$ Among the 28 persons consuming the bear meat, 21 had clinical manifestations of trichinellosis and most $(90 \% ; n=19)$ were serologically positive for Trichinella species antibodies. ${ }^{26}$ Among the 21 confirmed cases, the median incubation period was 19 d (range 6-34 d); all patients had a rash (Figure 2), 95\% $(n=20)$ had fever, $81 \%(n=17)$ had myalgias, and $48 \%$ $(n=10)$ had facial edema. ${ }^{26}$ All patients were treated with albendazole or mebendazole with or without prednisolone, and all recovered. ${ }^{6}$ Trichinella larvae were isolated from samples of the bear meat consumed but could not be precisely speciated by DNA sequencing and were presumed to be the nongenotyped species, Trichinella T9 (Table 2). ${ }^{26}$

In a 2008 follow-up investigation of an outbreak of serologically confirmed trichinellosis in 8 patients who had consumed raw soft-shelled turtle meat in Taiwan, most patients were symptomatic with fever $(88 \%)$, myalgia (88\%), and periorbital swelling (38\%) (Figure 3). ${ }^{27}$ All patients were treated with albendazole or mebendazole, and all recovered. ${ }^{27}$ Although all patients had serological evidence of antibodies to Trichinella species, the specific causative species could not be determined. ${ }^{27}$ However, the investigators concluded that $T$ papuae was the most likely parasite causing the outbreak because of its ability to infect amphibians and reptiles and its endemicity throughout Southeast Asia (Table 2). ${ }^{27}$

In summary, the global epidemiology of trichinellosis following the consumption of undercooked commercial pork products has shifted in most regions to infection following the consumption of raw or undercooked wild game meats, especially bear, moose, deer, walrus, wild boar, and formerly domesticated feral hogs. ${ }^{26,28-34}$ Nevertheless, trichinellosis outbreaks following consumption of 


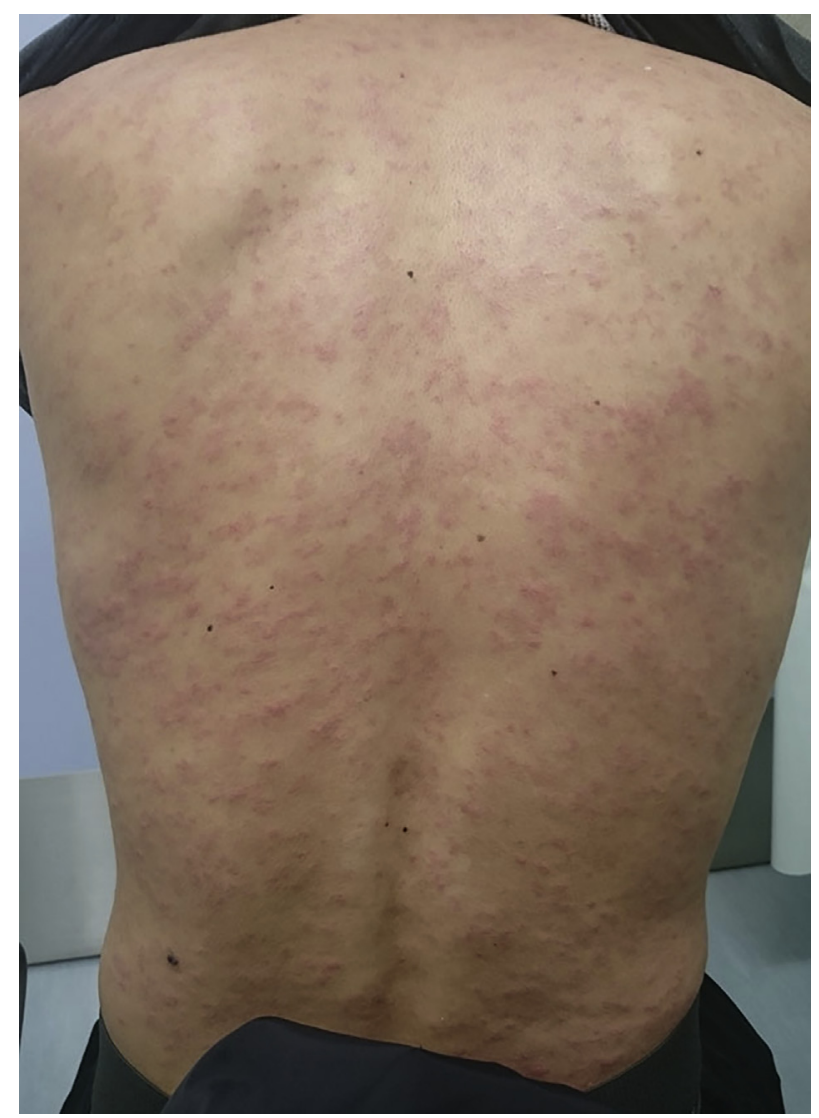

Figure 2. An intensely pruritic maculopapular rash developed on the back, face, and abdomen $24 \mathrm{~h}$ after a patient consumed an undercooked bear meat salad from which Trichinella species larvae were subsequently isolated in Japan (2016). Source: Tada et al. ${ }^{35}$ United States Centers for Disease Control and Prevention (CDC). Available at: https://wwwnc.cdc. gov/eid/article/24/8/17-2117-f2, https://www.cdc.gov/nczved/divisions/ dfbmd/diseases/coccidioidomycosis/. Public domain.

raw and undercooked home-raised swine, feral hogs, and wild boar continue to occur in pockets of Tibet and Southeast Asia (Cambodia, Laos, Vietnam, Thailand) where traditional raw pork dishes (salapao) are very popular and often consumed by mountainous tribes during religious celebrations and feasts (Laotian larb). ${ }^{32-34}$

\section{THE CLINICAL MANIFESTATIONS OF TRICHINELLOSIS}

The minimum infectious dose of Trichinella larvae is unknown, but the clinical manifestations of trichinellosis increase as the parasite burden increases. Light infections may be entirely asymptomatic. A travel history and a history of raw or undercooked meat ingestion are critical for early diagnosis, treatment, and prevention of complications.

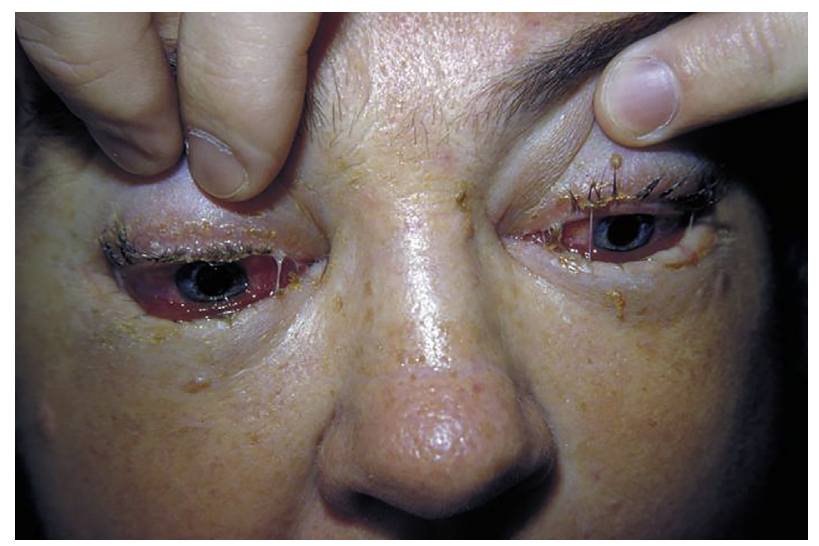

Figure 3. The ocular chemosis of trichinellosis is characterized by bilateral periorbital swelling, eyelid edema, purulent eyelid gland discharge, conjunctival injection, and proptosis. It may develop days to weeks after consumption of undercooked meat infected with Trichinella species larvae and resolves rapidly following treatment with corticosteroids and albendazole or mebendazole. Source: United States Centers for Disease Control and Prevention (CDC), Public Health Information Library (PHIL), PHIL ID\# 342. CDC Content Provider: Valerie Ng, MD, PhD. Available at: https://phil.cdc.gov/Details.aspx? pid=342. Public domain.

Adult worm migration during the enteral phase of infection causes the earliest manifestations of infection, with nausea, vomiting, sweating, abdominal pain, and diarrhea that are often overlooked or attributed to self-limiting viral gastroenteritis. ${ }^{9}$ The incubation period for the enteral phase onset is determined by parasite burden and ranges from $12 \mathrm{~h}$ to $2 \mathrm{~d}$ after consumption of contaminated meat. ${ }^{5,9}$ Later larval migration during the parenteral phase of infection causes more significant clinical manifestations often considered pathognomonic for trichinellosis, including fever, anorexia, malaise, abdominal pain and distension, chest pain and dyspnea, myalgias, pruritic skin rashes, periorbital and facial edema, orbital chemosis, conjunctival and retinal hemorrhages, and subungual splinter hemorrhages (Figures 2, 3, and 4). 5,9,35 The incubation period for the parenteral phase onset is also set by parasite burden and ranges from 5 to $7 \mathrm{~d}$ after the onset of the enteral phase. ${ }^{5,9}$ From $10 \mathrm{~d}$ to $2 \mathrm{wk}$ after the consumption of infected meat, the encysting phase begins, with fever, intense muscular pain in the largest striated muscles, and dyspnea from diaphragm involvement. ${ }^{5,9}$ Fever and muscle pain usually resolve 1 to $6 \mathrm{wk}$ after all migrating larvae encyst. Although fatalities are rare, larval encysting throughout vital organs may result in fatalities from sepsis or thromboembolism or from heart, kidney, liver, or brain damage. ${ }^{5,9}$

In areas where autochthonous and imported case outbreaks of trichinellosis are rarely reported, the differential diagnosis of trichinellosis, which initially manifests with nonspecific signs and symptoms, should include acute 


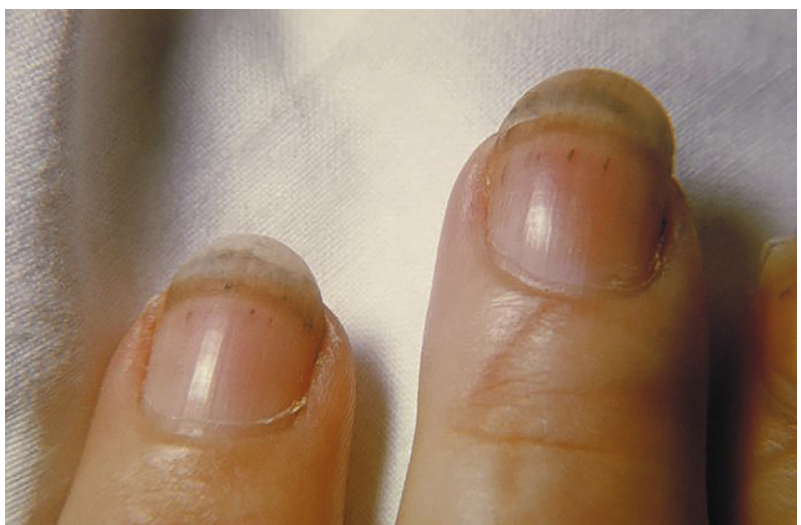

Figure 4. Subungual splinter-like hemorrhages in the nail beds beneath the fingernails may develop days to weeks after consumption of undercooked infected meat infected with Trichinella species larvae and resolve rapidly following treatment with albendazole or mebendazole. Source: United States Centers for Disease Control and Prevention (CDC), Public Health Information Library (PHIL), PHIL ID\# 2859. CDC Content Provider: Dr. Thomas F. Sellers. Available at: https://phil.cdc. gov/Details.aspx?pid=2859. Public domain.

gastroenteritis, appendicitis, leptospirosis, bacterial sepsis, influenza, AIDS, community-acquired pneumonia, myocarditis, heart failure, acute coronary syndrome, and any other helminthic infection characterized by the pulmonary migration of parasites (Loeffler's syndrome). ${ }^{5}$

\section{THE LABORATORY DIAGNOSIS OF TRICHINELLOSIS}

As the phases of infection progress, laboratory tests will demonstrate increasing peripheral eosinophilia, typically greater than $7 \%$ of the total white blood cell count or greater than 1000 eosinophils per microliter. ${ }^{5}$ Other nonspecific indicators of infection may include elevated peak creatine phosphokinase levels $\left(>0.5 \mathrm{mg} \cdot \mathrm{mL}^{-1}\right)$ indicative of muscle encystment damage, elevated peak lactic acid levels $(>2.0$ $\left.\mathrm{mmol} \cdot \mathrm{L}^{-1}\right)$ indicative of sepsis, and elevated peak troponin levels $\left(>0.23 \mathrm{ng} \cdot \mathrm{mL}^{-1}\right)$ indicative of myocardial encystment damage. ${ }^{5}$

Serologic evidence of infection is established by demonstrating elevated Trichinella-specific antibodies to the excretory/secretory antigens of $T$ spiralis using enzymelinked immunosorbent assay (ELISA). ${ }^{36}$ Serum-specific $\mathrm{IgE}$ antibodies will appear first in acute trichinellosis but are detected in few cases at the onset of infection because of their short half-life in serum. ${ }^{37}$ The most sensitive method of serodiagnosis recommended by the International Commission on Trichinellosis is the detection of antiTrichinella IgG by ELISA using excretory/secretory antigens of $T$ spiralis muscle larvae. ${ }^{38}$ Acute and convalescent

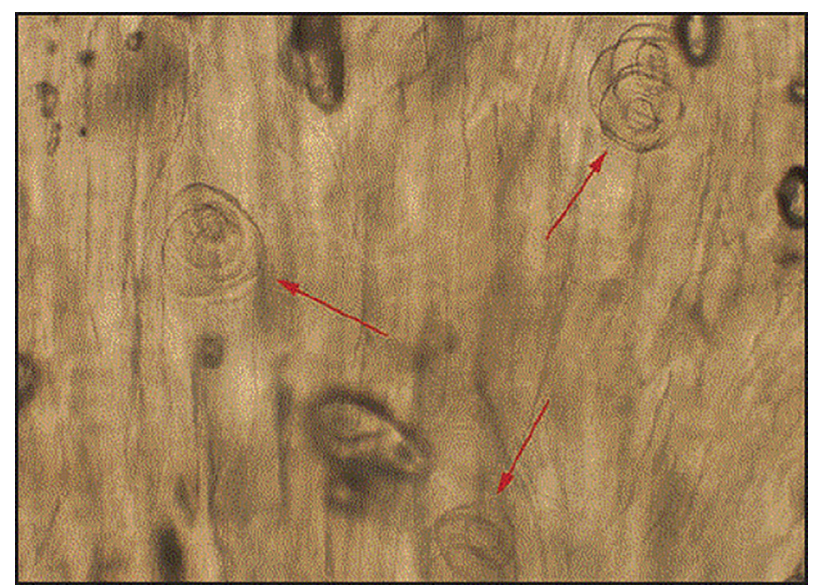

Figure 5. The microscopic (100x) image of an unstained touch preparation of Trichinella spiralis larvae encysted within raw wild boar meat (red arrows) implicated in a trichinellosis outbreak in California (2017). Source: Heaton et al. ${ }^{22}$ United States Centers for Disease Control and Prevention. Available at: https://www.cdc.gov/mmwr/volumes/67/wr/ mm6708a3.htm?s_cid=mm6708a3_w\#F1_down. Public domain.

ELISA tests at least $14 \mathrm{~d}$ apart are recommended because IgG antibodies may not be detected during the acute phase of infection at 12 to $14 \mathrm{~d}$ and only manifest at 20 to $35 \mathrm{~d}$ postinfection. ${ }^{39}$ To eliminate species cross-reactivity and to confirm the Trichinella species causing infection, molecular typing methods using polymerase chain reaction techniques based on the amplification of specific regions of the internal transcribed spacer and ribosomal RNA genes are required and usually are available only at state laboratories. ${ }^{40}$ The indirect immunofluorescence test on frozen sections of infected tissue is based on the cuticle surface antigens of the nematode and is the least sensitive diagnostic laboratory test because cross-reactions are common in patients with autoimmune diseases and other helminthiases. ${ }^{41,42}$

For further confirmation of infection in human and animal tissues, microscopic parasitological studies demonstrating encysted Trichinella larvae can be conducted on muscle biopsies, squash preparations, or impression (touch) smears, partially digested with pepsin and hydrochloric acid and taken from small slices of muscle (Figure 5) ${ }^{5,9}$ In animal meat consumed by humans, the parasite burden in suspected or infected meat can be quantitated microscopically in meat by counting the number of encysted larvae per gram of infected muscle tissue.

\section{THE TREATMENT OF TRICHINELLOSIS}

Treatment with antihelmintics, such as albendazole (400 mg orally twice daily for 10-14 d) or mebendazole (200-400 mg orally 3 times daily for 5-7 d), should 
begin immediately, if possible, and within $3 \mathrm{~d}$ of infection to reduce the degree of painful larval encystation. ${ }^{5,42,43}$ In addition, these drugs will inhibit the development of newly hatched larvae. ${ }^{5,42,43}$ In most cases, however, antihelmintic therapy will not begin until after symptoms of larval invasion and encystment in muscle have begun to cause fever, rash, periorbital and facial edema, and severe muscle pain. ${ }^{42,43}$ Because it is unknown how long adult female worms will keep depositing larvae into the small intestinal mucosa, antihelmintic therapy of all patients with confirmed infection may begin as late as 4 to $6 \mathrm{wk}$ after infection to reduce the burden of larval migration and muscular encystment and to manage muscle pain. ${ }^{42,43}$ Adjunctive therapy with analgesics is usually required for severe muscle pain. Glucocorticoid therapy with prednisone $(50 \mathrm{mg}$ orally per day) or prednisolone should be initiated in a monitored setting to reduce the risks of a Jarisch-Herxheimertype reaction with significant hypotension that can occur after the initiation of antihelmintic therapy in patients with large parasite burdens. ${ }^{42,43}$

\section{THE PREVENTION AND CONTROL OF TRICHINELLOSIS}

Freezing cuts of pork less than $15 \mathrm{~cm}$ (6 in) thick for $20 \mathrm{~d}$ at $-15^{\circ} \mathrm{C}\left(5^{\circ} \mathrm{F}\right)$ or for $3 \mathrm{~d}$ at $-20^{\circ} \mathrm{C}\left(-4^{\circ} \mathrm{F}\right)$ kills $T$ spiralis larval worms but will not kill the larval worms of other species of Trichinella that are freeze-resistant, such as $T$ britovi and $T$ nativa (Table 2). ${ }^{2,22,29}$ All wild game meat must be cooked thoroughly to an internal temperature of 71 to $74^{\circ} \mathrm{C}\left(160-165^{\circ} \mathrm{F}\right)$ or higher for 15 or more s to kill encysted larvae. ${ }^{2,22,29}$ Because thermometer calibration errors and internal bones can affect temperature uniformity throughout the meat, higher uniform temperatures and longer cooking times are recommended for all game meats. ${ }^{2,22,29}$ Cooking in microwave ovens, curing, drying, salting, and smoking will not kill encysted larvae and are not recommended. ${ }^{2,22,29}$ All meat handlers should adopt hygienic practices of washing hands with soap and water before and after handling raw meat and disinfecting all carving tables, cutting boards, knives, and other utensils used to prepare raw meats. ${ }^{2,22,29}$ In field situations, the surfaces and utensils used to prepare game meat should be cleaned first to remove all blood and tissue and then disinfected using boiling water and diluted sodium hypochlorite solutions $\left(5 \mathrm{~mL} \cdot 946 \mathrm{~mL}^{-1}\right.$ [1 teaspoon per quart of boiled water]). ${ }^{44}$ Lastly, the American Veterinary Medical Association recommends that hunters avoid killing, field dressing, handling, and eating meat from any wild game animal that appears to be ill. ${ }^{14}$

Finally, hunters have an obligation to participate in the control of Trichinella infections in wildlife and domestic animals. ${ }^{5,45}$ The only effective control measures that can be implemented by hunters to control the sylvatic cycle of trichinellosis are to avoid leaving animal carcasses and animal waste in the field after skinning and discarding of unwanted meat; all of these activities increase the probability of disease transmission to new hosts. ${ }^{5,45}$ A close association between a hunter's practice in discarding animal carcasses and waste in the field after skinning and dressing and the prevalence of trichinellosis in wildlife and in stray domestic animals has been confirmed in arctic and subarctic regions, Kazakhstan, New Hampshire, Spain, and European Russia. $^{45}$

\section{Conclusions}

Although trichinellosis surveillance programs and laws regulating commercial pork production have limited $T$ spiralis-caused trichinellosis in Europe and the United States, trichinellosis due to raw and undercooked wild boar and feral hog consumption continues to occur throughout Southeast Asia. In addition, trichinellosis due to consumption of raw or undercooked other infected game meats, such as bear, deer, moose, and walrus, continues to occur worldwide. Only adherence to hygienic practices when preparing wild game meats and cooking wild game meats to recommended internal temperatures can prevent the human transmission of trichinellosis. Wilderness medicine clinicians should be prepared to advise hunters and the public on the risks of game meat-linked trichinellosis and on how to prevent its transmission. Given the increasing prevalence of wild game meat-linked trichinellosis worldwide, clinicians should also be prepared to diagnose and treat trichinellosis to prevent complications and deaths.

Author Contributions: Primary contributing author and wrote the entire review (JHD); provided reference materials and reviewed the original manuscript (RJW, MJO).

Financial/Material Support: All financial/material support for JHD, RJW, and MJO was provided by departmental and institutional sources.

Disclosures: None.

\section{References}

1. Pozio E, Darwin Murrell K. Systematics and epidemiology of Trichinella. Adv Parasitol. 2006;63:367-439.

2. Wilson NO, Hall RL, Montgomery SP, Jones JL. Trichinellosis surveillance-United States, 2008-2012. MMWR Surveill Summ. 2015;64(1):1-8.

3. Roy SL, Lopez AS, Schantz PM. Trichinellosis surveillance-United States, 1997-2001. MMWR Surveill Summ. 2003;52(6):1-8.

4. Rostami A, Gamble HR, Dupouy-Camet J, Khazan H, Bruschi F. Meat sources of infection for outbreaks of human trichinellosis. Food Microbiol. 2017;64:65-71. 
5. Gottstein B, Pozio E, Nockler K. Epidemiology, diagnosis, treatment, and control of trichinellosis. Clin Microbiol Rev. 2009;22(1):127-45.

6. Murphy CM. Writing an effective review article. J Med Toxicol. 2012;8(2):89-90.

7. Pozio E, Hoberg E, La Rosa G, Zarlenga DS. Molecular taxonomy, phylogeny, and biogeography of nematodes belonging to the Trichinella genus. Infect Genet Evol. 2009;9(4): 606-16.

8. Krivokapich SJ, Pozio E, Gatti GM, Prous CL, Ribicich M, Marucci G, et al. Trichinella patagoniensis n. sp. (Nematoda), a new encapsulated species infecting carnivorous mammals in South America. Int J Parasitol. 2012;42(10):903-10.

9. Peters W, Pasvol G. Trichinosis. In: Peters W, Pasvol V, eds. Atlas of Tropical Medicine and Parasitology. 6th ed. Philadelphia, PA: Elsevier; 2007:238-40.

10. Capo VA, Despommier DD, Polvere RI. Trichinella spiralis: vascular endothelial growth factor is up-regulated within the nurse cell during the early phase of its formation. J Parasitol. 1998;84(2):209-14.

11. Forbes LB. The occurrence and ecology of Trichinella in marine mammals. Vet Parasitol. 2000;93(3-4):321-34.

12. Springer YP, Casillas S, Helfrich K, Mocan D, Smith M, Arriaga G, et al. Two outbreaks of trichinellosis linked to consumption of walrus meat-Alaska, 2016-2017. MMWR Morb Mortal Wkly Rep. 2017;66(26):692-6.

13. Dupouy-Camet J, Bourée P, Year H. Trichinella and polar bears: a limited risk for humans. J Helminthol. 2017;91(4): 440-6.

14. American Veterinary Medical Association. Disease Precautions for Hunters 2010. Available at: http://www.avma. org/resources/public-health/disease-precautions-hunters\# trichinellosis. Accessed January 31, 2020.

15. Watier-Grillot S, Vallee I, Lacour SA, Cana A, Davoust B, Marie JL. Strayed dogs as sentinels of Trichinella britovi infection in Kosovo. Parasite. 2011;18(3):281-3.

16. Dubey JP, Hill DE, Zarlenga DS. A Trichinlla murrelli infection in a domestic dog in the United States. Vet Parasitol. 2006;137(3-4):374-8.

17. Hill DE, Samuel MD, Nolden CA, Sundar N, Zarlenga DS, Dubey JP. Trichinella murrelli in scavenging mammals from south-central Wisconsin, USA. J Wildl Dis. 2008;44(3):629-35.

18. Meng XJ, Lindsay DS, Sriranganathan N. Wild boars as sources of infectious diseases in livestock and humans. Philos Trans R Soc Lond B Biol Sci. 2009;364(1530): 2697-707.

19. Loxano Becera JC, Gurtner De la Fuente V, Pozio E, Bernasconi E. Trichinellosis in immigrants in Switzerland. J Travel Med. 2012;19(3):195-7.

20. Fichi G, Stefanelli S, Pagani A, Luchi S, DeGennaro M, Gómez-Morales MA, et al. Trichinellosis outbreak caused by meat from a wild boar hunted in an Italian region considered to be at negligible risk for Trichinella. Zoonoses Public Health. 2015;62(4):285-91.

21. Turiac IA, Cappelli MG, Olivieri R, Angelillis R, Martinelli D, Prato R, et al. Trichinellosis outbreak due to wild boar meat consumption in southern Italy. Parasit Vectors. 2017;10(1):107.

22. Heaton D, Huang S, Shiau R, Casillas S, Straily A, Kong LK, et al. Trichinellosis outbreak linked to consumption of privately raised raw boar meat-California, 2017. MMWR Morb Mortal Wkly Rep. 2018;67(8):247-9.

23. Murrell KD, Pozio E. Worldwide occurrence and impact of human trichinellosis, 1986-2009. Emerg Infect Dis. 2011;17(12):2194-202.

24. Horsemeat-associated trichinosis-France. MMWR Morb Mortal Wkly Rep. 1986;35(18):291-2.

25. Murrell KD, Djordjevic M, Cuperlovic K, Sofronic LJ, Savic M, Djvordjevic M, et al. Epidemiology of Trichinella infection in the horse: the risk from animal product feeding practices. Vet Parasitol. 2004;123(3-4):223-33.

26. Tada K, Suzuki H, Sato Y, Morishima Y, Nagano I, Ishioka H, et al. Outbreak of Trichinella T9 infections associated with consumption of bear meat, Japan. Emerg Infect Dis. 2018;24(8):1532-5.

27. Lo YC, Hung CC, Lai CS, Wu Z, Nagano I, Maeda T, et al. Human trichinosis after consumption of soft-shelled turtles, Taiwan. Emerg Infect Dis. 2009;15(12):2056-8.

28. Rodriguez E, Olmedo J, Ubeira FM, Blanco C, Garate T. Mixed infection, Trichinella spiralis and Trichinella britovi, in a wild boar hunted in the Province of Caceres (Spain). Exp Parasitol. 2008;119(3):430-2.

29. Larter NC, Forbes LB, Elkin BT, Allaire DG. Prevalence of Trichinella spp. in black bears, grizzly bears, and wolves in the Dehcho Region, Northwest Territories, Canada, including the first report of $T$. nativa in a grizzly bear from Canada. $J$ Wild Dis. 2011;47(3):745-9.

30. Hall RL, Lindsay A, Hammond C, Montgomery SP, Wilkins PP, da Silva AJ, et al. Outbreak of human trichinellosis in Northern California caused by Trichinella murrelli. Am J Trop Med Hyg. 2012;87(2):297-302.

31. Trichinellosis cases-Alaska, 2005-2014. Epid Bull State of Alaska. 2015;6:1-2.

32. Cui J, Wang ZQ, Xu BL. The epidemiology of human trichinellosis in China during 2004-2009. Acta Trop. 2011;118(1): $1-5$.

33. Suwansrinon K, Wilde H, Burford B, Hanvesakul R, Sitprija V. Human trichinellosis from Laos. J Travel Med. 2007;14(4):274-7.

34. Van De N, Thi Nga V, Dorny P, Vu Trung N, Ngoc Minh P, Trung Dung D, et al. Trichinellosis in Vietnam. Am J Trop Med Hyg. 2015;92(6):1265-70.

35. Astudillo LM, Arlet PM. Images in clinical medicine. The chemosis of trichinosis. N Engl J Med. 2004;351(5):487.

36. Wang ZQ, Shi YL, Liu RD, Jiang P, Guan YY, Chen YD, et al. New insights on serodiagnosis of trichinellosis during window period: early diagnostic antigens from Trichinella spiralis intestinal worms. Infect Dis Poverty. 2017;6(1):41.

37. Bruschi F, Moretti A, Wassom D, Piergili Fioretti D. The use of a synthetic antigen for the serological diagnosis of human trichinellosis. Parasite. 2001;8(2 Suppl):S141-3.

38. Gamble HR, Pozio E, Bruschi F, Nockler K, Kapel CM, Gajadhar AA. International Commission on Trichinellosis: 
recommendations on the use of serological tests for the detection of Trichinella infections in animals and man. Parasite. 2004;11(1):3-13.

39. Van Knapen F, Franchimont JH, Verdonk AR, Stumpf J, Undeutsch K. Detection of specific immunoglobulins (IgG, $\operatorname{IgM}, \operatorname{IgA}, \operatorname{IgE})$ and total $\operatorname{IgE}$ levels in human trichinosis by means of enzyme-linked immunosorbent assay (ELISA). Am J Trop Med Hyg. 1982;31(5):973-6.

40. Zarlenga DS, Chute MB, Martin A, Kapel CM. A multiplex PCR for unequivocal differentiation of all encapsulated genotypes of Trichinella. Int J Parasitol. 1999;29(11):1859-67.

41. Yera H, Andiva S, Perret C, Limonne D, Boireau P, DupouyCamet J. Development and evaluation of a Western blot kit for diagnosis of human trichinellosis. Clin Diagn Lab Immunol. 2003;10(5):793-6.
42. Robert F, Weil B, Kassis N, Dupouy-Camet J. Investigation of immunofluorescence cross-reactions against Trichinella spiralis by western blot (immunoblot) analysis. Clin Diagn Lab Immunol. 1996;3(5):575-7.

43. Capo V, Despommier DD. Clinical aspects of infection with Trichinella spp. Clin Microbiol Rev. 1996;9(1): 47-54.

44. Cleaning \& sanitizing the kitchen using inexpensive household food-safe products. Available at: https://extension.colostate. edu/docs/pubs/foodnut/kitchen-sanitize.pdf. Accessed January $31,2020$.

45. Pozio E, Casulli A, Bologov VV, Marucci G, La Rosa G. Hunting practices increase the prevalence of Trichinella in wolves from European Russia. J Parasitol. 2001;87(6): 1498-501. 